\title{
1 Emergent vulnerability to intensive coastal anthropogenic disturbances in
}

\section{2 mangrove forests}

\author{
Yangfan $\mathrm{Li}^{\mathrm{a}}{ }^{\mathrm{b}}$, Zhen Zhang ${ }^{\mathrm{a}}$, Yi Yang ${ }^{\mathrm{a}}$, Yi Li ${ }^{\mathrm{a}} \mathrm{b}^{\mathrm{b}}$
}

4 a Key Laboratory of Coastal and Wetland Ecosystems (Ministry of Education), Fujian Provincial Key Laboratory

5 for Coastal Ecology and Environmental Studies, College of the Environment and Ecology, Xiamen University,

6 Xiamen, China

7 b Southern Marine Science and Engineering Guangdong Laboratory (Zhuhai), Zhuhai, China

\section{Abstract}

Mangrove forests, as one of the most productive coastal ecosystems in tropical and subtropical

11 areas, provide multiple valuable ecosystem services for human well-being. Mangrove coverage

12 has been declining dramatically across much of developing regions due to extensive coastal

13 anthropogenic disturbances such as reclamation, aquaculture, and seawall construction. As

14 coastal human activities increase, there is urgent need to understand not only the direct loss, but

15 also the vulnerability of mangroves to anthropogenic disturbances. In this study, we evaluated

16 spatial pattern of mangrove vulnerability based on the conceptual framework of "Exposure-

17 Sensitivity-Resilience" using geospatial datasets in mainland China. We find that within all

1825,829 ha mangroves in five coastal provinces of mainland China in 2015 , nearly $76 \%$ of

19 mangroves was exposed or threatened by anthropogenic disturbances. Coastal reclamation and

20 aquaculture were the key threats causing mangrove vulnerability. The overall distribution of high,

21 medium and low vulnerability was following similar trend of aquaculture distribution, which

22 suggests aquaculture was the greatest anthropogenic disturbance agent to mangroves. Hotspot

23 regions for mangrove vulnerability are located at the developing provinces such as Guangxi and 
24 Hainan. This study provides the first spatially explicit evidence of the vulnerability of mangrove

25 forests to intensive coastal anthropogenic disturbances at national scale, cloud serve as a

26 benchmark for navigating coastal ecological redline management and coastal ecosystem

27 restoration.

28 Keywords: mangroves; human activities; reclamation; urbanization; aquaculture; seawall 


\section{Introduction}

30 Global assessments indicate that coastal tropical and subtropical areas are threatened by the

31 greatest urbanization rates, suggesting an alarming to the conservation of coastal ecosystems in

32 this regions and their associated ecosystem services (Branoff, 2017; Friess et al., 2016; Rocha et

33 al., 2018; Seto et al., 2012). Mangrove provides essential ecosystem services to coastal

34 community, including products provision, cultural services, carbon sequestration, water

35 purification, shoreline protection/regulation and biodiversity conservation (Bell \& Lovelock,

36 2013; Crooks et al., 2018; Estoque et al., 2018; Friess \& Webb, 2014). However, intensive

37 anthropogenic disturbances caused by rapid coastal development exacerbates degradation of

38 coastal systems. Critical functions of coastal wetland ecosystems have been eroded by global-

39 scale anthropogenic pressures, which leads to irreversible land use and cover change, massive

40 biodiversity loss and overloaded land-based sources of pollution (Duke et al., 2014; Wang et al.,

41 2018).The world's area of mangrove forests has decreased by about $35 \%$ globally from 1980 to

422000 and experienced a decline of $1.97 \%$ annually from 2000 to 2012 (Hamilton \& Casey, 2016;

43 Valiela et al., 2001), about 3-5 times greater than that of terrestrial forest loss (Duke et al., 2014).

44 Coastal reclamation and conversion of mangroves to aquaculture or agriculture creates pressure

45 on mangrove ecosystems and has thus been a major driver of mangrove destruction (Flores-de-

46 Santiago et al., 2017; Mukherjee et al., 2014; Spalding, 2010). Numerous studies have quantified

47 increasing coastal reclamation and modifications over time, with demonstrated the deleterious

48 effects of urban, agricultural, aquaculture, and infrastructure development on mangrove

49 ecosystem (Hamilton \& Friess, 2018; Rivera-Monroy et al., 2017). Global sustainability science

50 increasingly recognize the changes of structure and function taking place in ecosystem, 
51 understanding which ecological functions are vulnerable to anthropogenic disturbances is key to

52 sustainable development (Richards \& Friess, 2016).

53 Vulnerability defines the degree to which a system or system component is susceptible to

54 experience harm due to exposure to a perturbation or stressor which mostly associated with

55 environmental, social change, and from the absence of capacity to adapt (Adger, 2006; Turner II

56 et al., 2003; White, 1974). Vulnerability analysis in coupled social-ecological systems draws on

57 three major concepts: exposure, sensitivity and resilience (IPCC, 2014; Turner II et al., 2003).

58 Through many years of studies on mangroves under climate change to reveal its distinct

59 structures and process (Lovelock et al., 2015; Duke et al., 2014; Webb et al., 2013; Xu et al.,

60 2016), there remains limited conceptual framework or model for the vulnerability of mangroves

61 to anthropogenic disturbances (Branoff, 2017; Mukherjee et al., 2014; Ventura \& Lana, 2014).

62 Predictions of mangrove vulnerability around cities are mostly reported in low- and lower-

63 middle-income regions of Africa, Latin America and India (DasGupta \& Shaw, 2013; Elmqvist

64 et al., 2013; Nortey et al., 2016).

65 Urbanization, in terms of landscape pattern changes, is particularly detrimental to degradation

66 of mangrove in the Anthropocene. Human-induced coastal reclamation, as a typical land use

67 change, is one of the key drivers of mangrove deforestation (Richards \& Friess, 2016).

68 Landscape changes caused by the human activities of coastal ecosystems can produce both direct

69 and indirect effects on the long term sustainability of mangrove wetlands and coastal

70 communities (Koh \& Khim, 2014; Yim et al., 2018). These changes raise questions such as: how

71 to identify the pattern of vulnerable mangroves to multiple environmental changes, and what are

72 principal threats to local mangroves? This recognition requires revisions and enlargements in the

73 basic design of vulnerability assessments, including the capacity to treat coupled social- 
74 ecological systems and those linkages within and without the systems that affect their

75 vulnerability.

76 Here, our aim was to evaluate the spatial pattern of mangrove vulnerability to coastal

77 anthropogenic disturbances in mainland China, the regions where experienced a rapid and

78 unprecedented process of urbanization. Our specific research questions were: (1) what is the

79 spatial pattern of mangrove distribution across mainland China? (2) what is the spatial pattern of

80 mangrove vulnerability to reclamation in mainland China? (3) what are the principle disturbance

81 agents to mangroves? For addressing these three questions, we firstly mapped the mangrove

82 extent for mainland China by using high-resolution Google Earth images and visual

83 interpretation, and subsequently developed a methodology to evaluate the vulnerability of

84 mangrove forests to three coastal anthropogenic disturbances (i.e., reclamation, aquaculture, and 85 seawall).

\section{$87 \quad 2$ Study area}

88 Since half of global mangrove areas are distributed within $25 \mathrm{~km}$ of urban centers inhabited by

89 dense human population (McLeod \& Salm, 2006; Millennium Ecosystem Assessment, 2005),

90 more than $90 \%$ of the world's mangroves are destroyed or threatened by diverse forms of human

91 activities in recent decades (Mcleod et al., 2011; Murray et al., 2018; Silliman et al., 2009).

92 Alarming losses of mangrove cover have occurred in most of developing areas of China due to

93 extensive coastal reclamation, deforestation, engineering and urbanization. Although mangroves

94 in China cover only $0.14 \%$ of the global mangrove area, one third of mangrove species can be 
95 found in this region (Romañach et al., 2018), suggesting that valuable contribution of mangrove

96 conservation in China to biodiversity conservation in global scale.

97 Natural mangroves grow along the southeast coast from Fujian Province to Hainan Province

$98\left(18^{\circ} 12^{\prime}-27^{\circ} 20^{\prime} \mathrm{N}\right)$. Planted mangroves are scattered within boundary of natural mangroves. To

99 protect local mangrove ecosystems, there are 35 conservation areas and several Ramsar

100 Convention sites in China, e.g., Dongzhaigang Mangrove Nature Reserve in Hainan Province,

101 Fujian Zhangjiangkou National Mangrove Nature Reserve.

102 Extensive coastal reclamation occurred in rapid urbanizing metropolitans of mainland China,

103 such as Bohai bay, Yangtze River delta and Pearl River delta, was responsible for approximately

104950,000 ha coastal wetlands loss and consequently ecosystem service decrease in recent years

105 (Sajjad et al., 2018; Tian et al., 2016). According to the statistical data from the State Oceanic

106 Administration, People's republic of China in 2015, the impacts of coastal reclamation on

107 ecosystem services resulted in the loss in wetlands of about $\$ 31,000$ million, which accounts for

$1086 \%$ of ocean economy in China (State Oceanic Administration, 2016).

109

\section{Materials and Methods}

$111 \quad$ 3.1 Mangrove mapping

112 For assessing the spatial vulnerability of mangroves, we firstly mapped the extent of mangrove

113 forest in mainland China using artificial visual interpretation. Processes of mangrove

114 interpretation included extracting mangroves with difference sources of base map (global

115 mangrove datasets, Landsat images, etc.) and modification with filed verification in each

116 province. Prior to interpretation, we imported the global mangrove distribution vector data in 
1172000 (https://www.usgs.gov/) as a base map and selected some mangrove samples in all five

118 provinces as test examples for mangrove identification. By modifying these samples under the

119 guidance of mangrove experts, mangroves are shown as dark green ribbon pattern and uniform

120 texture feature along coastline (Fig. S1). To eliminate visual interference from salt marsh species

121 (e.g., Spartina alterniflora), we selected Google Earth images in winter 2015 because mangroves

122 can be more easily identified during dormant season of salt marshes (Fig. S2). Meanwhile,

123 considering tidal inundation to mangroves, we compared the images of different time period in

124 same areas and selected images with low tide. This procedure helped to eliminate the error in

125 extracting submerged mangroves. Ultimately, we saved the mangrove layer in Google Earth and

126 exported to ArcMap 10.2. After interpretation with remote sensing images, we verified

127 mangrove area by field survey from February 2016 to March 2018 to examine interpretation

128 accuracy of mangrove forest map. We selected 56 mangrove validation sites and identified

129 mangrove distribution using Unmanned Aerial Vehicle (UAV) vertical photography and field

130 survey. About 758 UAV images were used to create a confusion matrix indicating the producer's

131 and user's accuracy. Availability of aerial photographs in our study area facilitated ground truth

132 process in evaluating accuracy of classified mangroves.

$134 \quad 3.2$ Detection of anthropogenic disturbances

$135 \quad$ 3.2.1 Reclamation activities

136 Reclamation is defined as the conversion of coastal land to agricultural, industrial, and urban

137 land use (Tian et al., 2016). We assume that the impacts of reclamation activities are decreasing

138 with distance to artificial coastline, which means the longer distance to coastline the less

139 negative influences of reclamation activities to local mangroves. We created a buffer of coastline 
140 sourced from Sajjad et al., 2018, and the buffer radius is set as $900 \mathrm{~m}$ since this distance covers

$14198 \%$ of mangroves in mainland China. Then we conduct a stress-gradient analysis in three levels

142 of pressure based on $300 \mathrm{~m}$ intervals (Fig. 1, adapted from Sutton-Grier et al., 2015). The coastal

143 area within the first $300 \mathrm{~m}$ buffer zone adjacent to reclamation suggests the highest level of

144 pressure from reclamation activities on mangroves, which was assigned with a high-pressure

145 value.

a

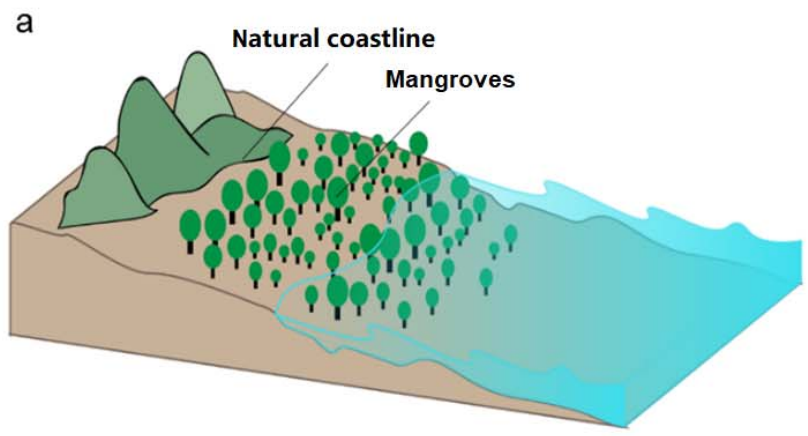

146

147

Fig. 1. A schematic diagram of the spatial distribution of the reclamation pressure.

\subsubsection{Aquaculture pollution}

Aquaculture pollution dataset contains two layers-aquaculture ponds and tidal creek, which are

151 the main sources of pollutants in local ecosystem. Muddy sediments and wastewater of

152 aquaculture ponds produce highly concentrated pollutants that lead to degradation of mangrove

153 system (Xin et al., 2014). Aquaculture ponds data was extracted from the layer of coastline in

154 our previous study (Sajjad et al., 2018), tidal creek was detected by visual image interpretation

155 based on Google Earth. We created buffer zones for both layers with distance of $70 \mathrm{~m}, 140 \mathrm{~m}$

156 and $210 \mathrm{~m}$ separately to model stress-gradient analysis regarding aquaculture pollution (Fig. 2, 
157 adapted from Sutton-Grier et al., 2015). High threats from aquaculture pollution was assigned in

158 the coastal area of $70 \mathrm{~m}$ buffer zone, while relative low threats within the $210 \mathrm{~m}$ buffer zone.

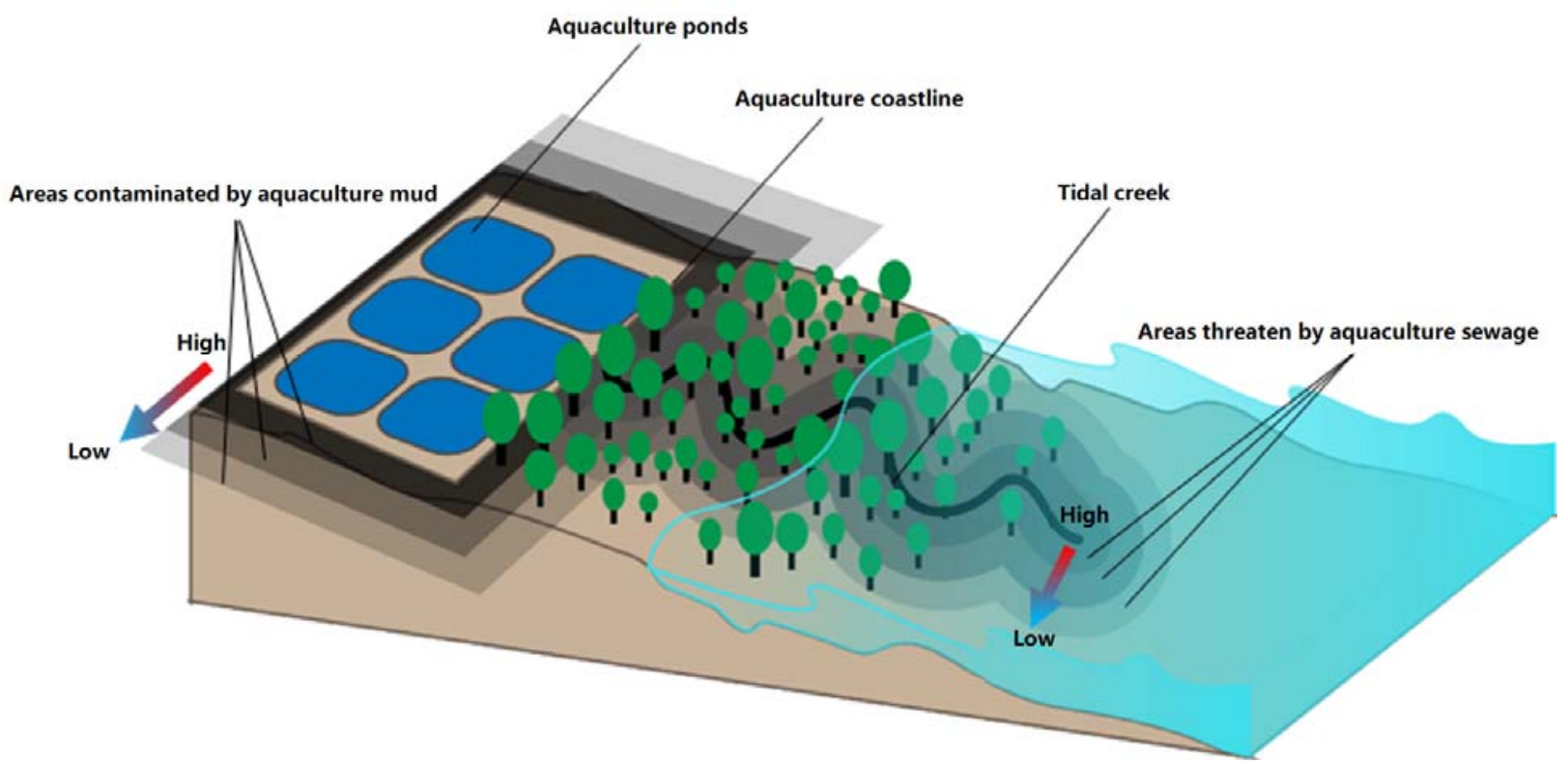

160 Fig. 2. A schematic diagram of the spatial distribution of the aquaculture pollution pressure.

\subsubsection{Seawall}

163 With the increase of dam construction and large reservoir projects in developing countries

164 (Moran et al., 2018; Shi et al., 2018), large area of landscape transformed from natural coastline

165 to seawall. The newly built impervious surface areas squeeze coastal zone toward ocean with

166 increasing risk of flood (Doody, 2013; Ramesh et al., 2015). Three buffer zones were created

167 along the claimed coastline with the distances of $300 \mathrm{~m}, 600 \mathrm{~m}$ and $900 \mathrm{~m}$ to create stress-

168 gradient layer of flood risk (Fig. 3, adapted from Sutton-Grier et al., 2015). In this case, $300 \mathrm{~m}$

169 buffer zone is the area with the lowest flood threat, which is opposite to the threat distribution of

170 reclamation threat. 


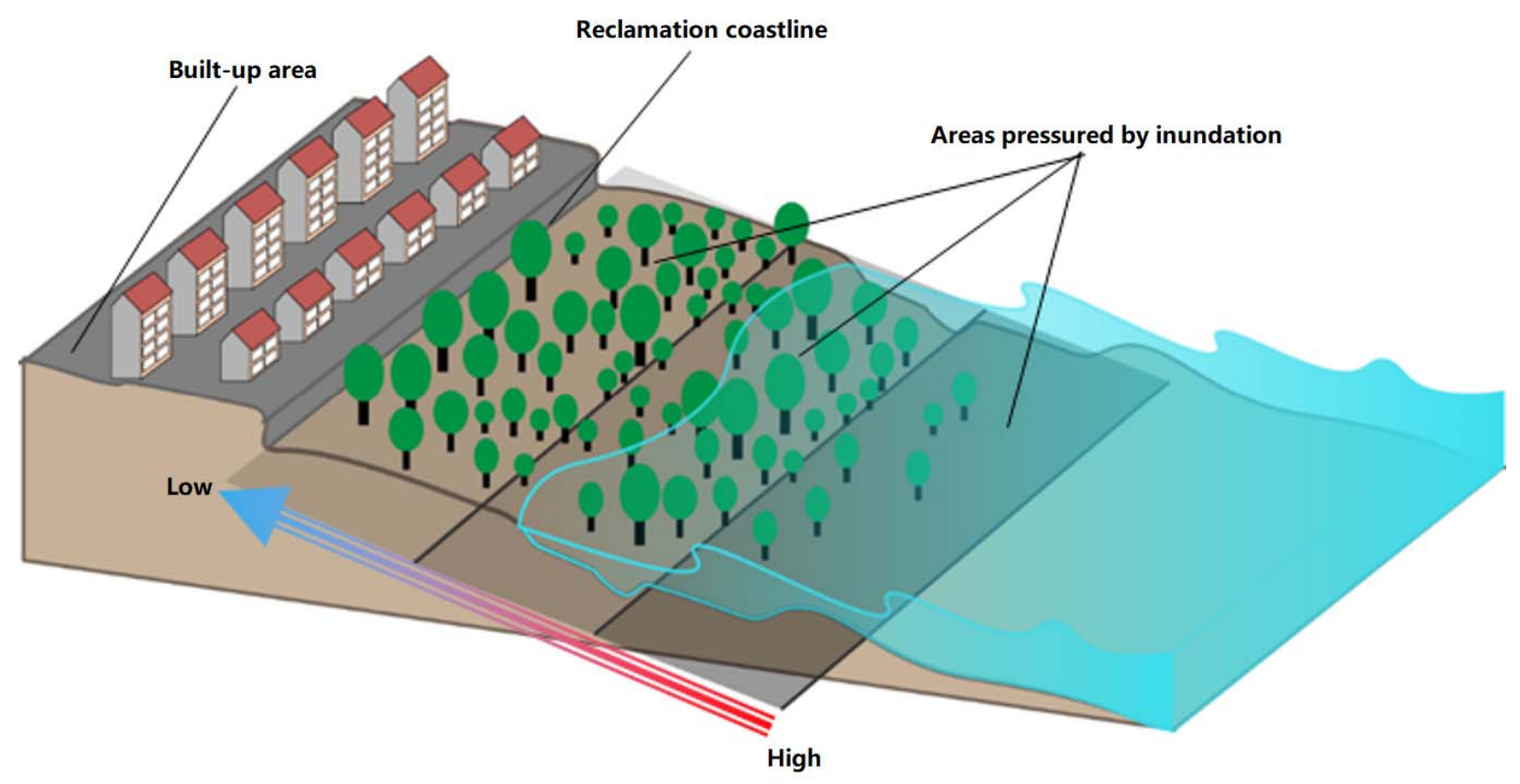

Fig. 3. A schematic diagram of the spatial distribution of the seawall barrier pressure.

\section{$174 \quad 3.3$ Vulnerability assessment}

175 Referring to the vulnerability framework proposed by Turner II et al. (2003), we proposed a 176 spatial assessment framework to evaluate mangrove vulnerability using InVEST model, which is

177 a spatially-explicit modelling tool for assessing ecosystem services and would return a suite of

178 results in a raster format to evaluate ecosystem states. (Sharp et al., 2015). We used the Habitat

179 Risk Assessment submodule from InVEST model with inputs of all anthropogenic disturbance 180 agents to local mangroves. Vulnerability of mangroves was characterized by integrating three 181 subsystems: exposure, sensitivity and resilience (Fig. 4; Table S1).

182 Exposure index represents the amount and intensity of anthropogenic stressors to mangroves. 183 Exposure value was divided by the overlapped area of mangroves and reclamation and 
184 reclamation pressure intensity. Sensitivity index indicates negative impacts of reclamation on

185 mangroves, and was quantified by mangrove loss area and mangrove species change. Resilience

186 characterizes the ability of mangroves to maintain their structural and functional stability in the

187 process of and after reclamation disturbances. And it was quantified by mangrove species

188 number, ratio of non-endangered species, regional ecological management, and potential

189 restoration areas for mangroves. We then clustered these indexes to corresponding vulnerability

190 ranking of low (value $=1$ ), moderate (value=2) and high (value=3) using $K$-means algorithm (See

191 Supplementary material for more details).

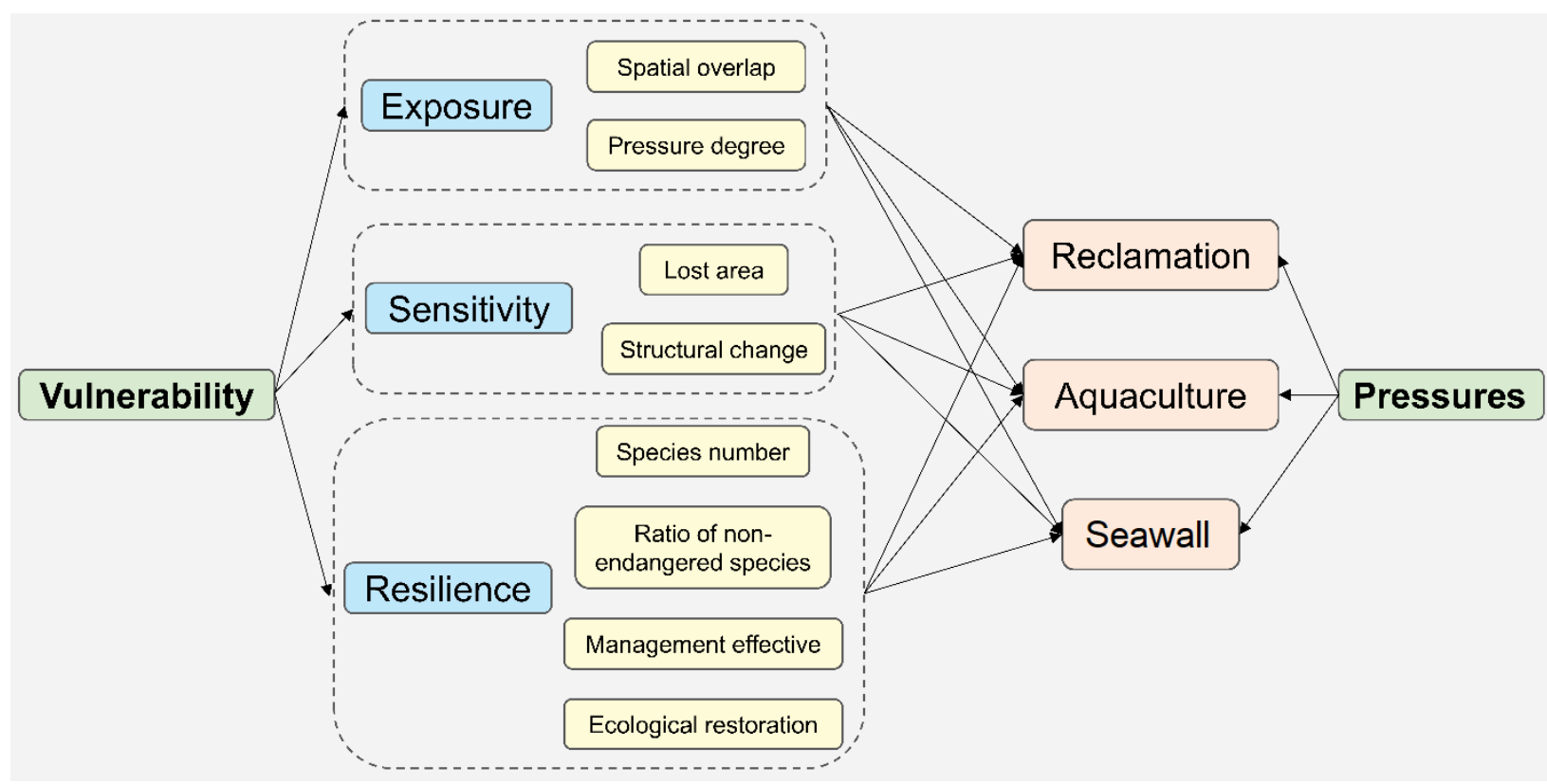

Fig. 4. Indexes of mangrove vulnerability to anthropogenic disturbance pressures.

195 Exposure indicators represent risks of mangrove while experiencing vast reclamation activities,

196 which describes characteristics and components of exposure to reclamation. Inputs of exposure 197 included polygons of mangroves and reclamation with attributes about mangrove distribution 
198 and 12 types of reclamation pressure. Sensitivity is a dose-response of mangrove system to

199 reclamation, it is an interaction between reclamation and mangrove conditions. Sensitivity, as an

200 interlinked factor between the other two aspects, was calculated with potential loss and potential

201 structure change of mangroves to different reclamation pressures. Resilience refers to recovery

202 capacities of mangrove system to reclamation activities, resilience was represented by both two

203 internal indicators (species numbers and ratio of non-threaten species) and external resilience

204 indicator (ecological management).

205 Vulnerability of mangroves can be characterized by degree to which mangrove is likely to

206 experience damage during coastal development. Vulnerability of mangroves is predicated on

207 trade-offs between economic development and coastal ecosystem services maintenance, as they

208 are affected by interconnections operating at different spatiotemporal and functional scales.

209 Based on vulnerability framework, the Habitat Risk Assessment model in InVEST was used to

210 calculate spatial vulnerability of mangroves in each province while adapting to coastal

211 reclamation (Sharp et al., 2015). Combination of vulnerability framework and InVEST model

212 produces spatial qualitative estimate of potential risks in terms of vulnerability value while

213 exposed to reclamation, which differentiates areas with relatively high or low exposure to

214 reclamation threats.

215

2164 Results

$217 \quad 4.1$ General distribution of mangroves

218 In total, 25,829 ha mangroves were identified in five coastal provinces of mainland China in

2192015 (Fig. 5), 96.14\% of which were distributed in southern part of coastal provinces (Hainan, 
220 Guangxi and Guangdong Province), mainly located in the Beibu Gulf Economic Rim (the

221 economic region surrounding around China's southwestern coastal area). About 11,115 ha (43\%)

222 mangroves was classified in Guangdong Province, where many coastal areas are dominated by

223 sedimentary environments. Followed by Guangxi Province with a number of 9,297 ha

224 mangroves, the third largest area of mangroves was 4,420 ha in Hainan Province. About 963 ha

225 and 34 ha mangroves were detected in Fujian Province and Zhejiang Province respectively.

226

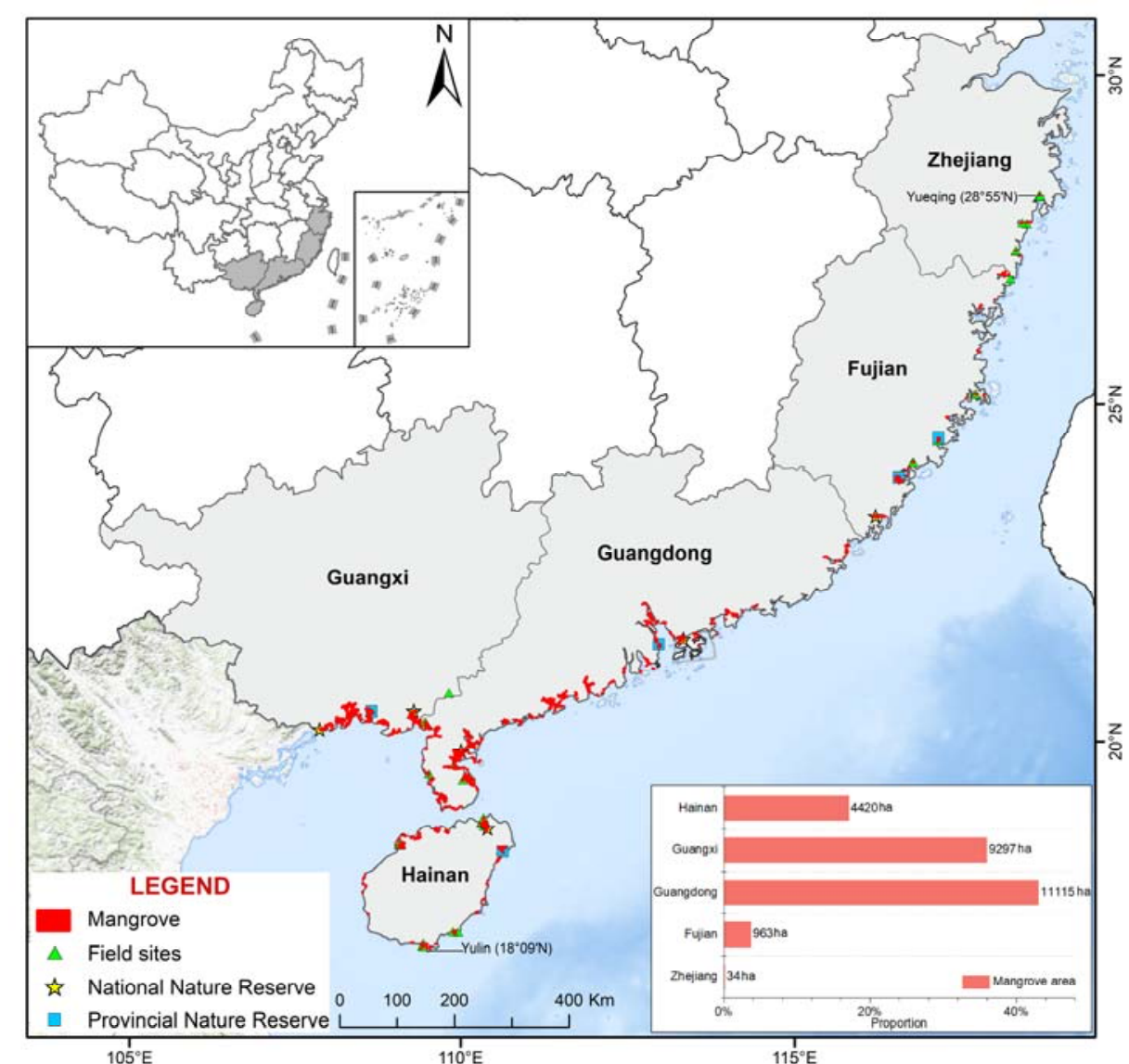

Fig. 5. Mangroves distribution in five coastal provinces.

\subsection{Principal disturbance agents to mangroves}

Landscape conversion from natural coastline to artificial coastline was the key driver of mangrove degradation. By overlapping coastline and mangroves, we found that only $7 \%$ of mangrove was adjacent to natural coastline types (Fig. 6). Most of mangroves were exposed to 
232 anthropogenic disturbances caused by redeveloped coastlines, where $64 \%$ of mangrove was

233 located near aquaculture ponds and $29 \%$ of mangrove was threatened by filled land. It suggests

234 that $93 \%$ of mangrove was squeezed by human-built bank and dam toward ocean, and they were

235 threatened by floods on the marine side.

236 In a local scale, reclamation activities in Zhejiang Province resulted in the highest density of

237 filled coastline among all coastal provinces. Followed by Guangxi Province, high percentage

238 (98\%) of artificial coastline was adjacent to mangrove, due to large areas of aquaculture feeding

239 ponds. In all these five provinces, the highest ratio (30\%) of natural coastline adjacent to

240 mangroves appeared in Fujian Province. Even though the coverage of aquaculture in Fujian,

241 Guangdong and Hainan Province were lower than that in Guangxi, but aquaculture land in all

242 provinces covered more than that of natural land. Guangdong was the province which has the

243 longest coastline both artificial and nature, followed by Guangxi, demonstrating that these two

244 provinces need to be given priority (Fig. 6b).

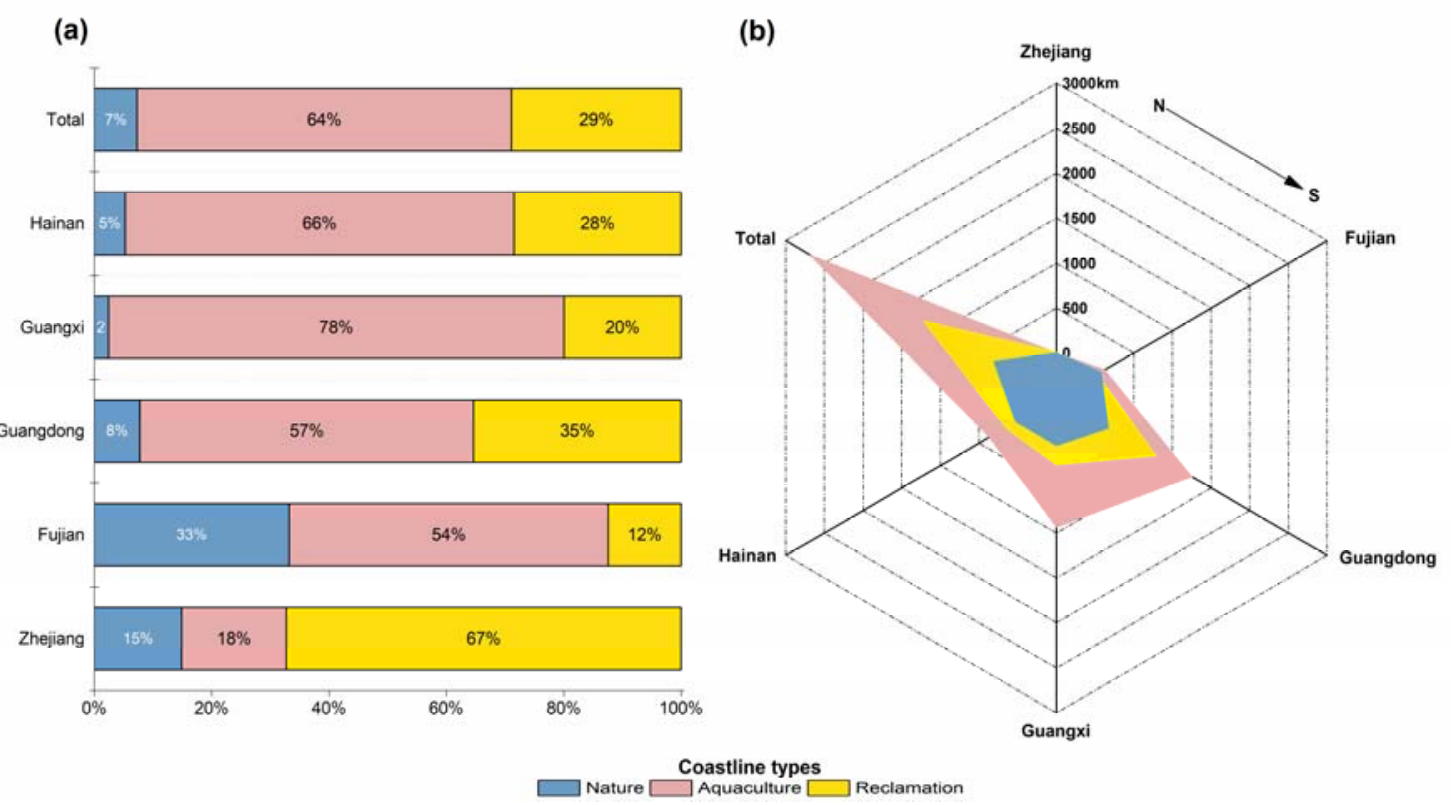

Fig. 6. Proportions (a) and lengths (b) of different coastline types in 2015. 
$248 \quad 4.3$ Spatial distribution of mangrove vulnerability

249 In this study, spatial distribution of vulnerability in mangroves was derived by combining

250 vulnerability framework and Habitat Risk Assessment (HAR) model in InVEST (Fig. 7). We

251 found that $29 \%$ of mangrove areas was identified under high vulnerability, only $24 \%$ of them

252 was estimated as area with low vulnerability. The average value of vulnerability in all five

253 provinces were ranked from high to low as Zhejiang, Hainan, Guangxi, Guangdong, and Fujian.

254 As can be seen from Fig. 8, all mangroves in Zhejiang Province were under high vulnerability,

255 which indicates high risk of degradation in this region. Mangroves in Zhejiang Province were

256 planted species, due to its climate conditions and high coverage of artificial coastline, there is

257 limited suitable natural coastal areas for mangroves. About $64.41 \%$ of mangroves in Hainan

258 Province were observed under high vulnerability, only $9.44 \%$ of them were remained in low

259 human influences. The main reason of such high vulnerability in this region was caused by

260 aquaculture pollution and high ratio of endangered species. Nearly $25 \%$ of mangroves in both

261 Guangxi and Fujian Province was classified with high vulnerability, it was because of marine

262 aquaculture and coastal redevelopment, all of which have led to significant degradation and 263 ecological disturbances to mangroves. 

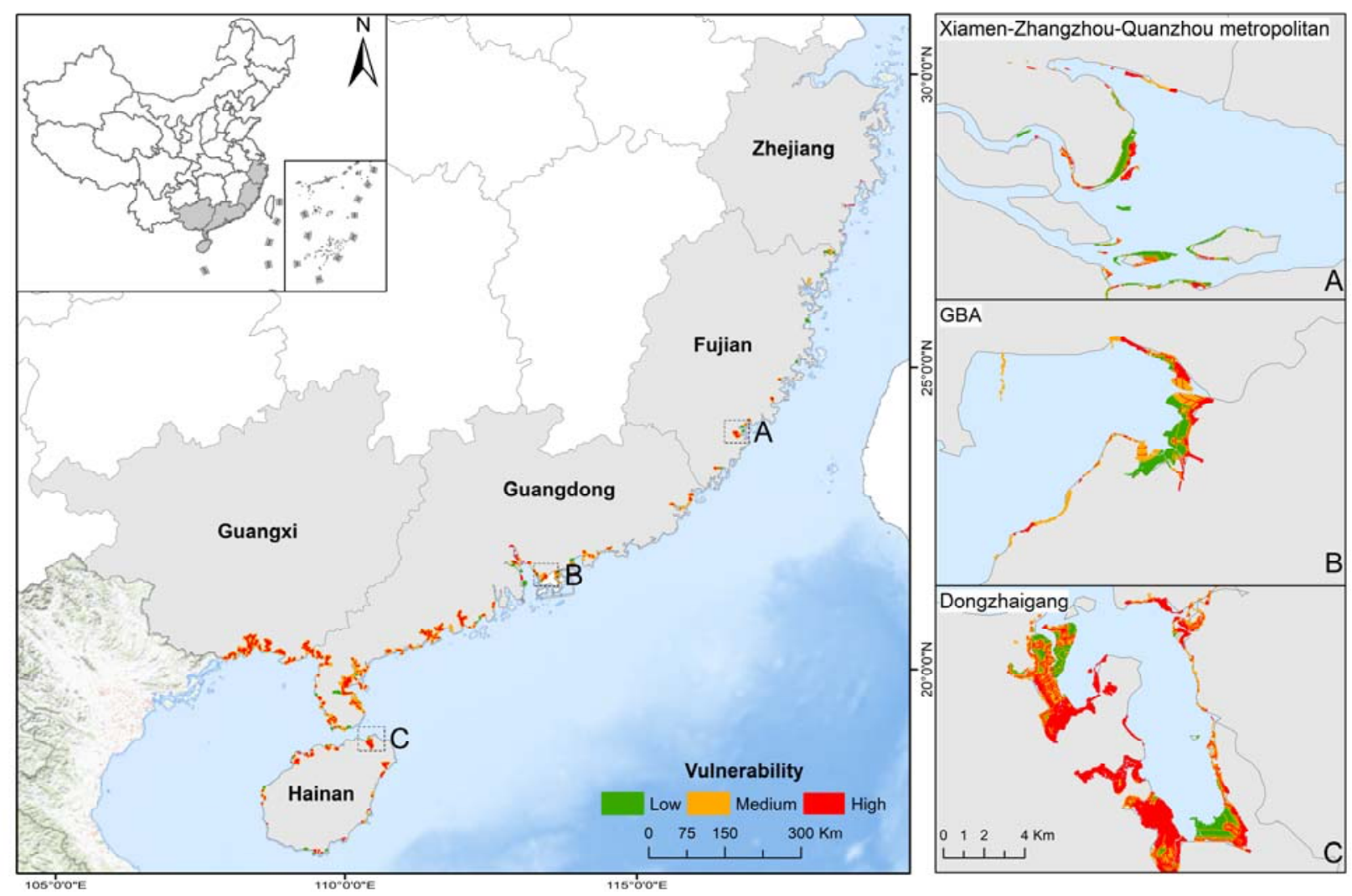

265 Fig. 7. Distribution of mangrove vulnerability to anthropogenic disturbances along China's

266 coastal area. (GBA: Guangdong-Hongkong-Macao Greater Bay Area).

268 Among all these selected vulnerability indicators, aquaculture and reclamation coastlines were

269 the key drivers of mangroves degradation. Areas with high vulnerability in Guangxi and Hainan

270 Province was found near large areas of aquaculture and reclamation. The overall distribution of

271 high, medium and low vulnerability was following similar trend (Fig. 8), the largest groups of

272 vulnerability (peak values) appeared in Guangxi, Guangdong and Hainan Province. However,

273 peak values of three levels of vulnerability were slightly different, while that of medium and low

274 vulnerability were in Guangxi Province, and mangroves in Hainan had the largest area of high 
275 vulnerability. In general, based on the distribution of coastline and vulnerability, we found that 276 aquaculture was primarily threats to high risk of mangroves degradation in these five provinces.
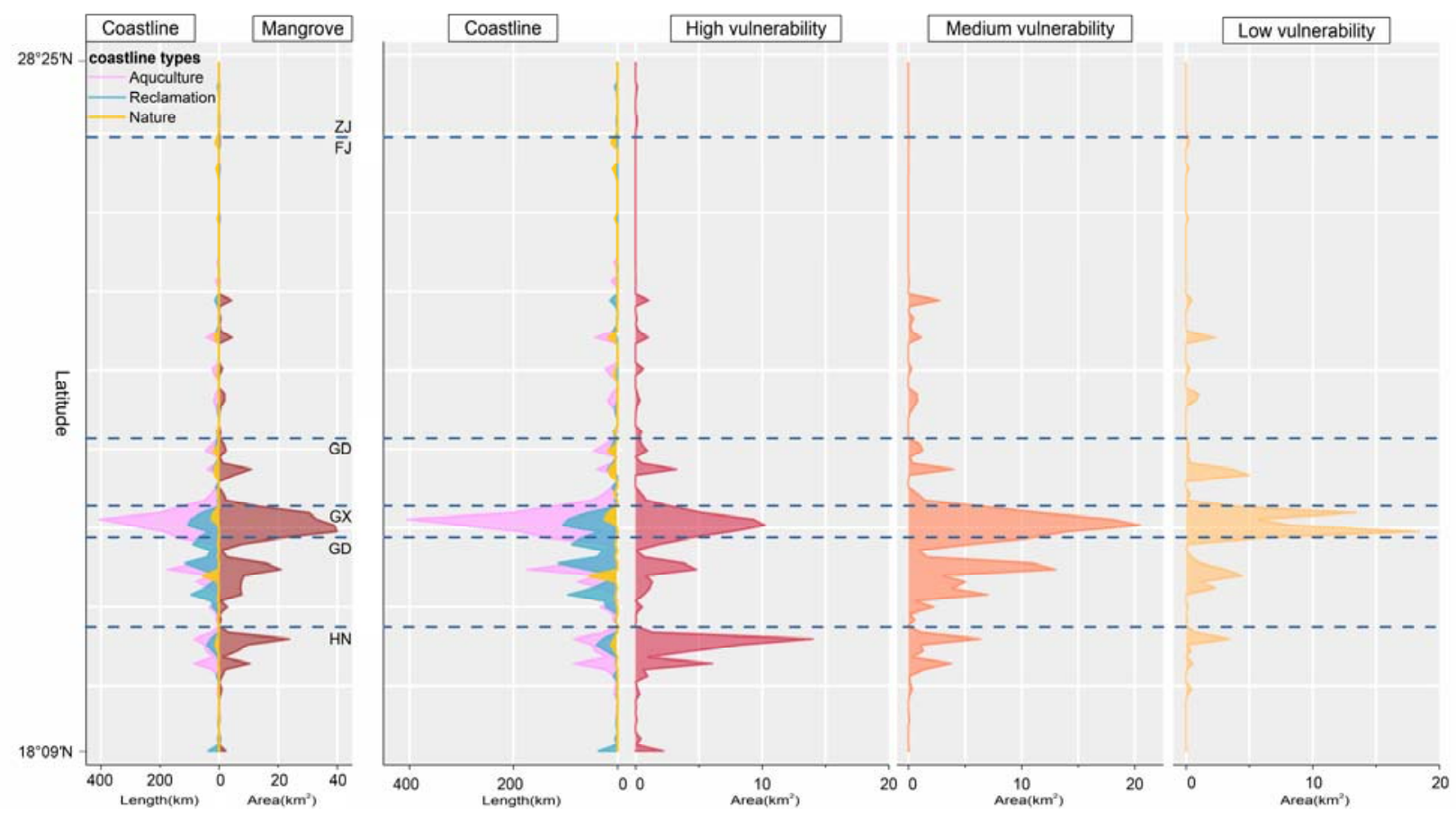

278 Fig. 8. Spatial distribution of coastline with mangrove and different level of vulnerability. The

279 left side of $\mathrm{Y}$ axis shows the latitude of different types of coastline (aquaculture, reclamation,

280 and natural) from Zhejiang Province to Hainan Province (ZJ: Zhejiang Province; FJ: Fujian

281 Province; GD: Guangdong Province; GX: Guangxi Province; HN: Hainan Province), the right

282 side of Y axis represents area of mangroves and different level of vulnerability spatially. The left

$283 \mathrm{X}$ axis is the length of mangroves and right $\mathrm{X}$ axis is the area of different level of vulnerability.

In a local scale, mangroves in urban agglomerations experienced higher vulnerability than that 286 rest of mangrove (Fig. 7). As the Guangdong-Hong Kong-Macao Greater Bay Area (GBA) 287 becomes an important economic zone in China, rapid urbanization in coastal areas lead to high 288 level of disturbance caused by human activities, which is the principal threat to local mangrove 
ecosystem. In the meantime, Guangdong Province has the largest area of mangrove in all five

290 provinces, which includes 7 natural protected areas for mangrove conservation. These protected

291 areas help to maintain key functions of local mangrove ecosystems under coastal reclamation.

292 The northern boundary of natural mangroves is located in Fujian Province, the Xiamen-

293 Zhangzhou-Quanzhou metropolitan in this Province was also exposed to relative high

294 vulnerability due to extensive reclamation activities. Even if protected in a national nature

295 reserve, mangroves in Dongzhaigang also faced serious threats due to the substantially increased

296 aquaculture ponds and construction area.

$297 \quad 4.4$ Accuracy assessment

298 Our results show that the map of mangrove forests in 2015 showed a high user's accuracy of

$29997.4 \%$ and producer's accuracy of $82.2 \%$. We also compared our results with similar research in

300 China to quantify the reliability of our interpretation (Jia et al., 2018). Detected total area of

301 mangroves $(25,829 \mathrm{ha})$ in our research was comparable with their results derived from Landsat

302 archive (22,419 ha). Due to the coarse resolution of Landsat archive $(30 \mathrm{~m})$, small mangrove

303 fragments in urban agglomeration identified in our study was not able to be classified by using

304 Landsat images. Therefore, the identified area of mangrove in our study is larger than their result.

305 The main difference between these two datasets was in the Pearl River Estuary and Xiamen-

306 Zhangzhou-Quanzhou metropolitan. In order to improve our accuracy of mangrove identification

307 in those regions, field investigation was carried out in summer time. Overall, the validation

308 results suggest that our mangrove map is mainly consistent with ground truth and similar

309 research in China. 


\section{Discussion}

3125.1 Impacts of principal threats on vulnerability distribution to local ecosystems

313 Due to continuous influences of coastal reclamation and aquaculture farming, mangroves are

314 exposed to dynamic and extensive threats in local region. Conversion of mangroves to

315 aquaculture ponds was encouraged by local governments, which becomes main income of

316 coastal regions. Among all types of coastal development activity in terms of land use change, the

317 most significant replacement of land use was aquaculture (64\% of total area), which leads to high

318 vulnerability of local mangroves.

319 As comparing all three levels of vulnerability distribution, we found that mangroves with

320 medium level of vulnerability was the most sensitive area to aquaculture factor. The overall

321 distribution pattern of medium vulnerability was coordinated with that of aquaculture. Except in

322 Zhejiang Province, aquaculture was the domain land use type in local mangrove areas, which

323 threatened more than half of mangroves in our study area. Threat of aquaculture in driving

324 mangrove deforestation is not only a problem in China, but also was found in southeast Asia

325 countries, such as Thailand, Indonesia, Vietnam, and the Philippines (Primavera, 2000; Richards

326 \& Friess, 2016).

327 Land redevelopment and infrastructure construction was another direct factor leading to

328 mangrove loss. Even it influences on vulnerability was not that significant as aquaculture, it

329 shows high correlations with high level of vulnerability, especially in the areas dominated by

330 reclamation coastlines in Hainan and Fujian Province. In those areas adjacent to long artificial

331 coastline, it also addresses high level of influence on vulnerability. Extensive and large area of

332 land reclamation occurred in Pearl River Delta (Guangdong Province) and Beibu Gulf (Guangxi

333 Province), these regions were shown with high vulnerability of mangrove degradation. Coastal 
334 artificial infrastructures, such as large industrial complexes, coastal interstate highways, and

335 airports, occupied areas suitable for mangrove growth, and accounted for $29 \%$ of total mangrove

336 areas in mainland China. Local government historically aimed to increase terrestrial land through

337 expansion towards ocean, especially in the most developed metropolises, such as GBA, Bohai

338 Bay (Tianjin Province), Hangzhou Bay (Zhejiang Province) and Min River estuary (Fujian

339 Province). High intensity of human disturbances toward ocean poses potential stress to mangrove

340 ecosystem, which reduce the buffer zone of mangroves in adapting to sea level rise.

$341 \quad 5.2$ Threats to local ecosystem services: habitats and biodiversity

342 Mangroves degradation and loss is not only bounded with mangrove ecosystem itself,

343 furthermore, spillover effects of mangroves degradation have significant influences on

344 ecosystem processes and services that they provide. Vulnerability of habitats and biodiversity

345 increased as structure and functionality of local ecosystems were challenged by anthropogenic

346 disturbances. Within areas of high vulnerability in mangroves, the most challenges to local

347 ecosystems were habitats degradation and biodiversity loss (Arkema et al., 2014). Nearly 35 ha

348 of mangrove disappeared in Futian mangrove conservation area because of city construction,

349 which leads to $39 \%$ of bird density loss and $45 \%$ of species reduction (Wang \& Wang, 2007).

350 Species extinctions can be followed by loss in functional diversity, particularly in mangroves

351 with high vulnerability. Further degradation in mangroves is likely to be followed by accelerated

352 functional losses. New top-down policies adopted by China's central government in 2016 has

353 imposed a conception of 'Redline', a boundary delineating a coastal strip in which to preserve

354 existing natural habitats, both for maintaining ecosystem function and to reduce conflicts

355 between natural processes (exacerbated by accelerated sea-level rise) and human settlements and

356 infrastructure. The Central Leading Group for Comprehensively Deepening Reforms of China 
357 approved a series of decisions of Redline policy in 2016. It comprises “Opinions on Delimiting

358 and Guarding Ecological Protection Redline", "Program for Wetland Protection and Restoration",

359 and "Rules on Coastal Line Protection and Utilization", which all emphasize the integration of

360 “One Redline Map” in China's coastal area. China's coastal Redline would be challenged by

3612020 in maintaining $35 \%(6,300 \mathrm{~km})$ of coastal line, which is the goal set by the central

362 government in protecting coastal line (Larson, 2015). Consequently, transitioning the coastline

363 from natural to artificial, through such methods as land claim or armoring, makes coastal areas

364 more vulnerable in terms of lost biodiversity and increased natural hazards (Arkema et al., 2015;

365 Steffen et al., 2015). Mangroves, as a typical coastal ecosystem included in the Redline area,

366 maintain key functions of local ecosystems, they also contribute to biodiversity conservation.

367 In 2018, China's governments announced to halt all coastal land reclamation that related to

368 business land use. But degradation of mangroves and irreversible landscape changes are still

369 challenging in maintain key functions of coastal ecosystems. As mangrove habitats are smaller or

370 fragmented, their essential ecosystem services may be lost within and beyond its boundary. The

371 central government should act quickly to nominate and protect vulnerable coastal sites, because

372 this would be consistent with the national Redline program and reclamation restoration. The

373 local governments of coastal provinces and cities should also proactively adopt effective

374 measures of their own, consistent with the national Redline policies, to protect vulnerable coastal 375 ecosystem.

\section{$376 \quad$ 5.3 Limitations}

377 There are some uncertainties in this study. The 900-m-buffer of coastal line and the $300 \mathrm{~m}$

378 interval in the buffer zone were chosen based on general distribution of mangroves in our study

379 area, which may different while implying to other regions. Moreover, in the current analysis, all 
3808 indicators in vulnerability assessment were treated with equal weight, which was set according

381 to current states of coastal region in China. This may various due to spatial heterogeneity in

382 different area, and need to adjust while applying to other cases.

383 Spatial outputs of mangrove vulnerability in this research provide a qualitative representation

384 of the relative contributions of anthropogenic disturbances to coastal vulnerability and highlight

385 the potential threats of reclamation in degrading mangrove ecosystems. Further information on 386 social, economic and coastal disaster are helpful in giving a comprehensive assessment of 387 mangroves ecosystem and better informing development strategies and permitting in setting 388 conservation priorities, monitoring deforestation and forest degradation.

\section{Conclusion}

391 Mangroves are under threats from different types of anthropogenic disturbances, coastal rapid

392 development, in terms of aquaculture and reclamation, has been a principal driver of mangrove

393 loss and degradation in China, and it becomes a growing concern worldwide. These two factors

394 were the main drivers of medium and high level of vulnerability. The continuously altered,

395 destroyed or transformed mangroves with high vulnerability is an early warning signal of 396 dramatic functionality loss of such major coastal ecosystem, which initiates more research of 397 mangrove in coastal urban environments.

398 Mangrove areas of high vulnerability suggest relative high level of combinate anthropogenic 399 disturbances from conversion for alternative uses (aquaculture, urban construction), which can 400 be prioritized for the development of conservation strategies. Distribution of mangrove 401 vulnerability also located the hotspots of key functionality loss and the vulnerable urban areas 
402 with high risk of storm surges or climate-related disasters. As we estimated, the major

403 disturbance agent to mangroves was aquaculture ponds, especially in Guangxi and Hainan

404 Provinces. These findings indicate an urgent need for implementing adaptive strategies to serve

405 mangroves from anthropogenic disturbances, and provides a spatially-explicit assessment for

406 navigating mangrove conservation.

407

\section{Acknowledgements}

409 We would like to appreciate Professor Wenqing Wang at Xiamen University who provided

410 valuable comments and suggestions. We also thank Dr. Diego Rybski in Potsdam Institute for

411 Climate Impact Research for his insightful comments and suggestions. Financial supports were

412 provided by the Programs of Science and Technology on Basic Resources Survey for the

413 Ministry of Science and Technology of China (No. 2017FY100701), the National Natural

414 Science Foundation of China (NSFC) Grants (No. 41976208 and 41701205), and the

415 Fundamental Research Funds for the Central Universities of China (No. 20720190089). 


\section{References}

418 Adger, W. N. (2006). Vulnerability. Global Environmental Change, 16(3), 268-281. https://doi.org/10.1016/j.gloenvcha.2006.02.006

Arkema, K. K., Verutes, G., Bernhardt, J. R., Clarke, C., Rosado, S., Canto, M., et al. (2014). Assessing habitat risk from human activities to inform coastal and marine spatial planning: a demonstration in Belize. Environmental Research Letters, 9(11), 114016. https://doi.org/10.1088/1748-9326/9/11/114016

Arkema, K. K., Verutes, G. M., Wood, S. A., Clarke-Samuels, C., Rosado, S., Canto, M., et al. (2015). Embedding ecosystem services in coastal planning leads to better outcomes for people and nature. Proceedings of the National Academy of Sciences, 112(24), 7390-

Bell, J., \& Lovelock, C. E. (2013). Insuring Mangrove Forests for Their Role in Mitigating Coastal Erosion and Storm-Surge: An Australian Case Study. Wetlands, 33(2), 279-289.

Branoff, B. L. (2017). Quantifying the influence of urban land use on mangrove biology and ecology: A meta-analysis. Global Ecology and Biogeography, 26(11), 1339-1356. https://doi.org/10.1111/geb.12638

434 Crooks, S., Sutton-Grier, A. E., Troxler, T. G., Herold, N., Bernal, B., Schile-Beers, L., \& Wirth, 435 T. (2018). Coastal wetland management as a contribution to the US National Greenhouse 436 Gas Inventory. Nature Climate Change, 8(12), 1109-1112. 437 https://doi.org/10.1038/s41558-018-0345-0 
438 DasGupta, R., \& Shaw, R. (2013). Changing perspectives of mangrove management in India-An analytical overview. Ocean \& Coastal Management, 80, 107-118. https://doi.org/10.1016/j.ocecoaman.2013.04.010

Doody, J. P. (2013). Coastal squeeze and managed realignment in southeast England, does it tell us anything about the future? Ocean \& Coastal Management, 79(Supplement C), 34-41.

Duke, N., Nagelkerken, I., Agardy, T., Wells, S., \& Van Lavieren, H. (2014). The importance of https://doi.org/10.1016/j.ocecoaman.2012.05.008

447 Elmqvist, T., Fragkias, M., Goodness, J., Güneralp, B., Marcotullio, P. J., McDonald, R. I., et al. mangroves to people: A call to action. United Nations Environment Programme World Conservation Monitoring Centre (UNEP-WCMC), Cambridge.

Estoque, R. C., Myint, S. W., Wang, C., Ishtiaque, A., Aung, T. T., Emerton, L., et al. (2018). 7088-1 Assessing environmental impacts and change in Myanmar's mangrove ecosystem service value due to deforestation (2000-2014). Global Change Biology, 24(11), 5391-5410. https://doi.org/10.1111/gcb.14409

Flores-de-Santiago, F., Serrano, D., Flores-Verdugo, F., \& Monroy-Torres, M. (2017). Application of a simple and effective method for mangrove afforestation in semiarid regions combining nonlinear models and constructed platforms. Ecological Engineering, 103, 244-255. https://doi.org/10.1016/j.ecoleng.2017.04.008 
Friess, D. A., \& Webb, E. L. (2014). Variability in mangrove change estimates and implications for the assessment of ecosystem service provision. Global Ecology and Biogeography, 23. https://doi.org/10.1111/geb.12140

Friess, D. A., Thompson, B. S., Brown, B., Amir, A. A., Cameron, C., Koldewey, H. J., et al. (2016). Policy challenges and approaches for the conservation of mangrove forests in Southeast Asia: Conservation of Mangrove Forests. Conservation Biology, 30(5), 933949. https://doi.org/10.1111/cobi.12784

Hamilton, S. E., \& Casey, D. (2016). Creation of a high spatio-temporal resolution global database of continuous mangrove forest cover for the 21 st century (CGMFC-21): CGMFC-21. Global Ecology and Biogeography, 25(6), 729-738.

Hamilton, S. E., \& Friess, D. A. (2018). Global carbon stocks and potential emissions due to https://doi.org/10.1111/geb.12449

473 Intergovernmental Panel on Climate Change (IPCC). (2014). IPCC Fifth Assessment Report mangrove deforestation from 2000 to 2012. Nature Climate Change, 8(3), 240-244. https://doi.org/10.1038/s41558-018-0090-4 (AR5): Climate Change 2014: Impacts,Adaptation, and Vulnerability. Part A: Global and Sectoral Aspects. Contributionof Working Group II to the Fifth Assessment Report of the IntergovernmentalPanel on Climate Change. (p. 169). Cambridge University Press,

Jia, M., Wang, Z., Zhang, Y., Mao, D., \& Wang, C. (2018). Monitoring loss and recovery of mangrove forests during 42 years: The achievements of mangrove conservation in China. 

https://doi.org/10.1016/j.jag.2018.07.025

482

483

484

485

486

487

Koh, C., \& Khim, J. S. (2014). The Korean tidal flat of the Yellow Sea: Physical setting, ecosystem and management. Ocean \& Coastal Management, 102, 398-414. https://doi.org/10.1016/j.ocecoaman.2014.07.008

Larson, C. (2015). Migratory bird populations in Asia are crashing as Yellow Sea habitat dwindles. Science, 350(6257), 150-152.

Lovelock, C. E., Cahoon, D. R., Friess, D. A., Guntenspergen, G. R., Krauss, K. W., Reef, R., et al. (2015). The vulnerability of Indo-Pacific mangrove forests to sea-level rise. Nature, 526(7574), 559-563. https://doi.org/10.1038/nature15538

McLeod, E., \& Salm, R. V. (2006). Managing mangroves for resilience to climate change. The World Conservation Union (IUCN), Gland, Switzerland.

Mcleod, E., Chmura, G. L., Bouillon, S., Salm, R., Björk, M., Duarte, C. M., et al. (2011). A blueprint for blue carbon: toward an improved understanding of the role of vegetated coastal habitats in sequestering $\mathrm{CO}_{2}$. Frontiers in Ecology and the Environment, 9(10), 552-560. https://doi.org/10.1890/110004

Millennium Ecosystem Assessment. (2005). Ecosystems and human well-being: synthesis. Washington, DC: Island Press.

Moran, E. F., Lopez, M. C., Moore, N., Müller, N., \& Hyndman, D. W. (2018). Sustainable hydropower in the 21st century. Proceedings of the National Academy of Sciences, 115(47), 11891-11898. https://doi.org/10.1073/pnas.1809426115 
Mukherjee, N., Sutherland, W. J., Khan, M. N. I., Berger, U., Schmitz, N., Dahdouh-Guebas, F., \& Koedam, N. (2014). Using expert knowledge and modeling to define mangrove composition, functioning, and threats and estimate time frame for recovery. Ecology and Evolution. https://doi.org/10.1002/ece3.1085

Murray, N. J., Phinn, S. R., DeWitt, M., Ferrari, R., Johnston, R., Lyons, M. B., et al. (2018). The global distribution and trajectory of tidal flats. Nature. https://doi.org/10.1038/s41586-018-0805-8

Nandy, S., \& Kushwaha, S. P. S. (2011). Study on the utility of IRS 1D LISS-III data and the classification techniques for mapping of Sunderban mangroves. Journal of Coastal

Nortey, D. D. N., Aheto, D. W., Blay., Jonah, F. E., \& Asare, N. K. (2016). Comparative Conservation, 15(1), 123-137. https://doi.org/10.1007/s11852-010-0126-z

Primavera, J. H. (2000). Development and conservation of Philippine mangroves: institutional Assessment of Mangrove Biomass and Fish Assemblages in an Urban and Rural Mangrove Wetlands in Ghana. Wetlands, 36(4), 717-730. https://doi.org/10.1007/s13157-016-0783-2

518 Ramesh, R., Chen, Z., Cummins, V., Day, J., D’Elia, C., Dennison, B., et al. (2015). Land-Ocean 519 Interactions in the Coastal Zone: Past, present \& future. Anthropocene, 12, 85-98. 520 https://doi.org/10.1016/j.ancene.2016.01.005 
521 Richards, D. R., \& Friess, D. A. (2016). Rates and drivers of mangrove deforestation in Southeast Asia, 2000-2012. Proceedings of the National Academy of Sciences, 113(2), 344-349. https://doi.org/10.1073/pnas.1510272113

524

Rivera-Monroy, V., Lee, S. Y., Kristensen, E., \& Twilley, R. (2017). Mangrove ecosystems: $a$ global biogeographic perspective. New York, NY: Springer International Publishing.

Rocha, J. C., Peterson, G., Bodin, Ö., \& Levin, S. (2018). Cascading regime shifts within and across scales, 31 .

Romañach, S. S., DeAngelis, D. L., Koh, H. L., Li, Y., Teh, S. Y., Raja Barizan, R. S., \& Zhai, L. (2018). Conservation and restoration of mangroves: Global status, perspectives, and prognosis. Ocean \& Coastal Management, $\quad 154, \quad 72-82$. https://doi.org/10.1016/j.ocecoaman.2018.01.009

Sajjad, M., Li, Y., Tang, Z., Cao, L., \& Liu, X. (2018). Assessing Hazard Vulnerability, Habitat Conservation, and Restoration for the Enhancement of Mainland China's Coastal Resilience. Earth's Future, 6(3), 326-338. https://doi.org/10.1002/2017EF000676

Seto, K. C., Güneralp, B., \& Hutyra, L. R. (2012). Global forecasts of urban expansion to 2030 and direct impacts on biodiversity and carbon pools. Proceedings of the National Academy of Sciences, 109(40), 16083-16088. https://doi.org/10.1073/pnas.1211658109

Sharp, R., Tallis, H. T., Ricketts, T., Guerry, A. D., Wood, S. A., Chaplin-Kramer, R., et al. (2015). InVEST +VERSION+ User's Guide. The Natural Capital Project, Stanford University, University of Minnesota, The Nature Conservancy, and World Wildlife Fund. Retrieved from http://data.naturalcapitalproject.org/nightlybuild/release_default/release_default/documentation/ 
543 Shi, H., Chen, J., Liu, S., \& Sivakumar, B. (2019). The role of large dams in promoting

544 economic development under the pressure of population growth. Sustainability, 11(10), 2965.

545 https://doi.org/10.3390/su11102965

546 Silliman, B. R., Bertness, M. D., \& Grosholz, E. D. (2009). Human Impacts on Salt Marshes: A

547 Global Perspective (First edition). Berkeley: University of California Press.

548 Spalding, M. (2010). World Atlas of Mangroves. London, UK: EarthScan.

549 State Oceanic Administration, People's republic of China. (2016). Report on the management of 550 the use of sea areas (2015). State Oceanic Administration, People's republic of China, Beijing, China.

Retrieved from http://www.soa.gov.cn/zwgk/hygb/hysyglgb/201604/t20160429_51327.html

553 Steffen, W., Richardson, K., Rockström, J., Cornell, S. E., Fetzer, I., Bennett, E. M., et al. (2015).

554 Planetary boundaries: Guiding human development on a changing planet. Science, 347(6223). https://doi.org/10.1126/science.1259855

556 Sutton-Grier A E., Wowk K., Bamford H. (2015). Future of our coasts: The potential for natural and hybrid infrastructure to enhance the resilience of our coastal communities, economies and ecosystems [J]. Environmental Science and Policy, 51, 137-148. https://doi.org/10.1016/j.envsci.2015.04.006

560 Tian, B., Wu, W., Yang, Z., \& Zhou, Y. (2016). Drivers, trends, and potential impacts of longterm coastal reclamation in China from 1985 to 2010. Estuarine, Coastal and Shelf Science, 170, 83-90. https://doi.org/10.1016/j.ecss.2016.01.006 
563 Turner II, B. L., Kasperson, R. E., Matson, P. A., McCarthy, J. J., Corell, R. W., Christensen, L.,

564 et al. (2003). A framework for vulnerability analysis in sustainability science.

565 Proceedings of the National Academy of Sciences, 100(14), 8074-8079.

566 https://doi.org/10.1073/pnas.1231335100

567 Valiela, I., Bowen, J. L., \& York, J. K. (2001). Mangrove Forests: One of the World's

568 Threatened Major Tropical Environments. BioScience, 51(10), 807. 569 https://doi.org/10.1641/0006-3568(2001)051[0807:MFOOTW]2.0.CO;2

570 Ventura, A. de O. B., \& Lana, P. da C. (2014). A new empirical index for assessing the 571 vulnerability of peri-urban mangroves. Journal of Environmental Management, 145, 572 289-298. https://doi.org/10.1016/j.jenvman.2014.04.036

573 Wang, Q., Li, Y., \& Li, Y. (2018). Realizing a new resilience paradigm on the basis of landwater-biodiversity nexus in a coastal city. Ocean \& Coastal Management. https://doi.org/10.1016/j.ocecoaman.2018.09.004

576 Wang, W., \& Wang, M. (2007). Mangroves in China (in Chinese). China Science Press.

577 Webb, E. L., Friess, D. A., Krauss, K. W., Cahoon, D. R., Guntenspergen, G. R., \& Phelps, J. (2013). A global standard for monitoring coastal wetland vulnerability to accelerated sealevel rise. Nature Climate Change, 3(5), 458-465. https://doi.org/10.1038/nclimate1756 York. 
582 Xin, K., Huang, X., Hu, J., Li, C., Yang, X., \& Arndt, S. K. (2014). Land use Change Impacts on

583 Heavy Metal Sedimentation in Mangrove Wetlands-A Case Study in Dongzhai Harbor

584 of Hainan, China. Wetlands, 34(1), 1-8. https://doi.org/10.1007/s13157-013-0472-3

585 Xu, Y., Shen, Z.-H., Ying, L.-X., Ciais, P., Liu, H.-Y., Piao, S., et al. (2016). The exposure, sensitivity and vulnerability of natural vegetation in China to climate thermal variability (1901-2013): An indicator-based approach. Ecological Indicators, 63, 258-272. https://doi.org/10.1016/j.ecolind.2015.12.023

589 Yim, J., Kwon, B.-O., Nam, J., Hwang, J. H., Choi, K., \& Khim, J. S. (2018). Analysis of forty 590 years long changes in coastal land use and land cover of the Yellow Sea: The gains or 591 losses in ecosystem services. Environmental Pollution, 241, 74-84. https://doi.org/10.1016/j.envpol.2018.05.058 